\title{
Interrelationships between obesity, blood pressure and metabolic profile in climacteric women
}

\author{
Inter-relações entre obesidade, pressão \\ arterial e perfil metabólico em \\ mulheres climatéricas
}

\author{
Vivianne Margareth Chaves Pereira REIS1 (iD) 0000-0001-8797-2678 \\ Rafael Silveira FREIRE2 ID 0000-0002-3560-2082 \\ Maria Fernanda Santos Figueiredo BRITO3 (iD) 0000-0001-5395-9491 \\ Lucinéia de $\mathrm{PINHO}^{3}$ (ID) 0000-0002-2947-5806 \\ Josiane Santos Brant ROCHA ${ }^{1}$ (D) 0000-0002-7317-3880 \\ Marise Fagundes SILVEIRA ${ }^{4}$ ID 0000-0002-8821-3160
}

\section{A B S T R A C T}

\section{Objective}

This study aimed to evaluate the interrelationships between obesity, blood pressure and metabolic profile in climacteric women.

\section{Methods}

This is a cross-sectional study with a random sample of 874 women, aged 40 to 65 years, assisted in Family Health Strategies units in Montes Claros, Minas Gerais, Brazil. A structural equation model was used to assess the interrelationships

\footnotetext{
1 Universidade Estadual de Montes Claros, Programa de Pós-Graduação em Ciências da Saúde, Departamento de Educação Física. Av. Prof. Rui Braga, s/n., Vila Mauriceia, 39401-089, Montes Claros, MG, Brasil. Corresponde to: VMCP REIS. E-mail: <viola.chaves@yahoo.com.br>.

2 Faculdades Unidas do Norte de Minas, Centro de Ciências da Saúde, Curso de Fisioterapia. Montes Claros, MG, Brasil.

${ }^{3}$ Universidade Estadual de Montes Claros, Programa de Pós-Graduação em Cuidado Primário em Saúde, Departamento de Saúde Mental e Coletiva. Montes Claros, MG, Brasil.

${ }^{4}$ Universidade Estadual de Montes Claros, Programa de Pós-Graduação em Ciências da Saúde, Departamento de Ciências Exatas. Montes Claros, MG, Brasil.

Article based from the thesis by VMCP REIS, entitled "Metabolic Syndrome in women in menopause: prevalence and associated factors". Universidade Estadual de Montes Claros; 2018.
}

How to cite this article

Reis VMCP, Freire RS, Brito MFSF, Pinho L, Rocha JSB, Silveira MF. Interrelationships between obesity, blood pressure and metabolic profile in climacteric women. Rev Nutr. 2021;34:e200136. https://doi.org/10.1590/1678-9865202134e200136 
between obesity, blood pressure and metabolic profile, adjusted for age. The variables blood pressure, obesity and metabolic profile were treated as constructs, which measurement models were developed using confirmatory factor analysis.

\section{Results}

It was observed that age has a positive and significant effect on blood pressure $(\beta=0.20 ; p<0.001)$ and obesity $(\beta=0.10$; $p=0.004)$. There was a direct and positive effect of obesity on blood pressure $(\beta=0.26 ; p<0.001)$ and on the metabolic profile $(\beta=0.10 ; p=0.037)$, adjusted for physical activity.

\section{Conclusion}

The simultaneous analysis of the relationships between age, obesity, blood pressure and metabolic profile in menopausal women suggests that, ageing has an effect on the increase of obesity and blood pressure, just as obesity increases blood pressure and changes the metabolic profile.

Keywords: Blood pressure. Climacteric. Metabolic profile. Obesity.

\section{RE S U M O}

\section{Objetivo}

Avaliar as inter-relações entre obesidade, pressão arterial e perfil metabólico em mulheres climatéricas.

\section{Métodos}

Trata-se de estudo transversal com amostra aleatória composta por 874 mulheres com idade entre 40 a 65 anos assistidas em unidades de Estratégias de Saúde da Família em Montes Claros, Minas Gerais, Brasil. Foi utilizado modelo de equação estrutural para avaliar as inter-relações entre obesidade, pressão arterial e perfil metabólico, ajustado pela idade. As variáveis pressão arterial, obesidade e perfil metabólico foram tratadas como construtos, cujos modelos de mensuração foram construídos utilizando-se a análise fatorial confirmatória.

\section{Resultados}

Observou-se que a idade exerce efeito positivo e significativo sobre a pressão arterial $(\beta=0,20 ; p<0,001)$ e a obesidade $(\beta=0,10 ; p=0,004)$. Houve efeito direto e positivo da obesidade na pressão arterial $(\beta=0,26 ; p<0,001)$ e no perfil metabólico $(\beta=0,10 ; \beta=0,037)$, ajustado por atividade física.

\section{Conclusão}

A análise simultânea das relações entre idade, obesidade, pressão arterial e perfil metabólico em mulheres no climatério sugere que o aumento da idade tem efeito sobre o aumento da obesidade e da pressão arterial, assim como a obesidade tem efeito positivo sobre o aumento da pressão arterial e sobre a alteração no perfil metabólico.

Palavras-chave: Pressão arterial. Climatério. Perfil metabólico. Obesidade.

\section{INTRODUCTION}

Climacteric is a phase of life characterized by endocrine changes such as reduction of ovarian follicles, estrogens and progesterones, which can affect women's health [1]. As a result of these hormonal reductions, women in this stage of life have a considerable increase in the risk of cardiovascular disease, which can be enhanced between the climacteric transition phases [2,3].

In this period, women are susceptible to the worsening of cardiovascular risk factors such as obesity, systemic arterial hypertension and dyslipidemia [4]. All of these components are interrelated, and obesity constitute a risk mechanism for the manifestation of dyslipidemia and systemic arterial hypertension [5]. It is noteworthy that in the climacteric there is a noticeable increase in obesity in the abdominal region, which has a modulating effect on the lipid profile, glucose intolerance, and, especially, on arterial hypertension [1].

There are studies in the literature that have investigated the risk factors associated with cardiovascular diseases. The majority though have adopted classic statistical analysis techniques, such as linear regression 
models, logistic, Poisson and Cox regression [6-16]. These models are made up of multiple independent variables, but are limited to a single relationship between the dependent variable and the independent ones. However, using a multivariate statistical technique that makes it possible to deal with the complexity of the correlations between different variables in a model will allow to know the interrelations simultaneously [17]. In this connection, this study aimed to investigate the interrelationships between obesity, blood pressure and metabolic profile in climacteric women.

\section{E T HO D S}

This is an excerpt from a cross-sectional population-based study called "Health Conditions of Climacteric Women" that investigated the health conditions of climacteric women. The population involved 30,018 women, aged 40 to 65 years, registered in 73 Family Health Strategies' (FHS) Units in the city of Montes Claros (urban and rural area), Minas Gerais, Brazil.

Since this is an epidemiological survey that sought to estimate the prevalence of different health problems of women in menopause, the sample size was established with the aim of estimating population parameters with a prevalence of 0.50 , with a $95 \%$ level of confidence and $5 \%$ margin of error. Correction was made for the design purpose, adopting a deff equal to 2.0 and adding $10 \%$ for the non-response rate. The sample calculation comprised a minimum of 836 women. It is noteworthy that this sample size met the assumptions for conducting structural equation modeling [17]. Exclusion criteria included women who underwent angioplasty, were pregnant, puerperal and bedridden.

The sampling was probabilistic by conglomerate in two stages: in the first stage, 20 FHS units were selected by Probability Proportional to Size (PPS) [18]. In the second stage, by Simple Random Sampling (SRS), 48 women were drawn in each selected unit, totaling 960 individuals. Out of these, 86 (8.9\%) did not agree to participate in the study, so that the final sample consisted of 874 women. After the random selection, a date was scheduled for filling out questionnaires, for anthropometric assessments and blood collection. This data survey was carried out, on the premises of the FHS units, by a trained and qualified team, composed of a doctor, a pharmacist, five university students from the nursing and physical education course and the investigator in charge.

The sample profile was described, considering the following variables: age in years (age groups: 40 to 45 years, 46 to 51 years and 52 to 65 years), marital status (with partner and without partner), skin color (not white and white), education (middle/higher, elementary II, elementary I), formal work (yes/no), physical activity (sedentary, irregularly active, active/very active) and climacteric phases (pre-menopause, peri-menopause and post-menopause). The short version of the International Physical Activity Questionnaire (IPAQ) was used to assess the practice of physical activity [19].

For the investigation of blood pressure, obesity and metabolic profile, the following variables were considered: Systolic Blood Pressure (SBP), Diastolic Blood Pressure (DBP), Waist Circumference (WC), Body Mass Index (BMI), Waist-to-Height Ratio (WHtR), Triglycerides (TG), High Density Lipoprotein (HDL-c) and glycemia

Blood pressure was measured using a calibrated digital aneroid sphygmometer, ONROM ${ }^{\circledR}$, positioned in the proximal region of the left upper limb to the antecubital fossa. Systolic blood pressure occurred at the first arterial sounds (phase I of Korotkoff sounds) and diastolic blood pressure occurred when they disappeared (phase $V$ of Korotkoff sounds). Two measurements were performed with the woman seated, after 5 minutes rest [20]. 
To measure WC, a flexible and inelastic measuring tape was used, positioned around the smallest curvature located between the ribs and above the umbilical scar. The BMI was assessed using the formula (weight/height). Weight was measured with the woman barefoot and with the least clothes possible, using the digital scale EKS 9800 Focus $^{\circledR}, 180 \mathrm{~kg}$. Height assessment was performed in an anthropometric position and barefoot, using a Sanny ${ }^{\circledR}$ stadiometer.

In the calculation of the WHtR, the formula waist circumference/height, both measured in centimeters, was used. Waist circumference was measured using a flexible and inelastic measuring tape positioned at the midpoint between the last costal arch and the antero-superior iliac crest [20].

For the analysis of biochemical parameters such as fasting glucose, fraction of HDLC and TG, the subjects underwent blood collection in fasting conditions for at least 12 hours. Serum TG levels were determined by the colorimetric enzymatic method. The HDLc level was obtained by selective precipitation of Low Density Lipoproteins (LDL) and Very Low Density Lipoproteins (VLDL), followed by dosing by enzymatic system, in a Cobas Mira S device [20].

Three latent variables were also used: blood pressure, obesity and metabolic profile. Blood pressure was treated as a construct conditioned by four manifest variables: systolic blood pressure in the $1^{\text {st }}$ and $2^{\text {nd }}$ measurement and diastolic blood pressure in the $1^{\text {st }}$ and $2^{\text {nd }}$ measurement. Obesity was estimated as a construct manifested by the variables WC, BMI and WHtR. The metabolic profile was developed using the variables TG, HDL and glycemia [21-24].

The theoretical model hypothesized in this study is shown in Figure 1, in which the manifest variables are represented by rectangles, the latent variables by ellipses and the associations by arrows (trajectories). The arrows represent the direction of the functional relationship between the variables: from the independent to the dependent variable $[17,25]$.

Categorical variables were described through their frequency distributions and the numerical variables through the mean, standard deviation, asymmetry ( $s k)$ and kurtosis ( $k u$ ) and 95\% confidence interval, corrected by the design effect (deff). The variables normality were assessed by the coefficients of asymmetry and kurtosis, considering that absolute values of sk greater than three and ku greater than ten indicate non-compliance with normality. All the variables observed, with the exception of age, were transformed on a logarithmic scale, since their asymmetry and kurtosis coefficients suggested severe non-compliance with normal distribution. In this phase, the statistical program IBM SPSS version 22.0 was used for data analysis.

Initially, measurement models were developed for the constructs blood pressure, obesity and metabolic profile through confirmatory factor analysis $[25,26]$. Standardized factorial weights $(\lambda)$ and percentages of the total variability of each variable explained by its construct $(\lambda 2)$ were estimated. The factorial validity of the measurement models was assessed by standardized factor weights $(\lambda)$, being considered adequate when $\lambda>0.50$ [17].

Then, the Structural Equation Modeling (SEM) shown in Figure 1 was adjusted, with direct effects estimated through standardized structural coefficients whose significance was assessed by the relationship between the value of the coefficient and its standard error (Critical Ratio - CR) [17,25-27].

The Bentler Comparative Fit Index (CFI), the Goodness of Fit Index (GOF) and the Tucker-Lewis Index (TLI) were used to assess the overall quality of the adjusted models, with values greater than 0.90 being considered adequate. Root Mean Square Error of Approximation (RMSEA) with a 90\% Confidence Interval (CI) was also used [17,25-27]. A $90 \% \mathrm{CI}$ for the RMSEA with an upper limit of less than 0.10 was considered to be an indicator of a reasonable fit. The absolute index $\chi 2 / \mathrm{gl}$ was also adopted, with an acceptable fit for values below five [17]. The models were adjusted using the IBM SPSS AMOS 22.0 statistical program. 


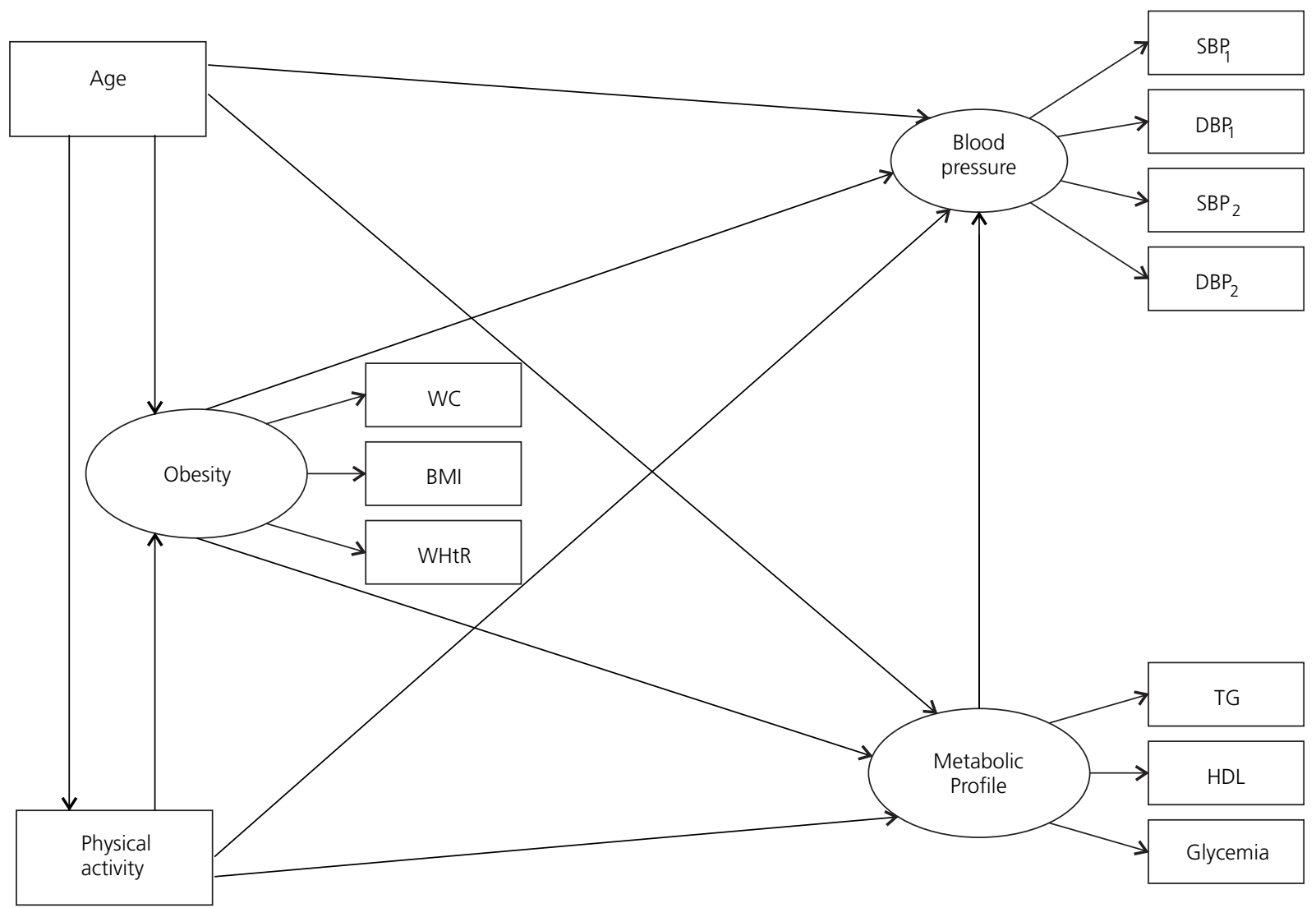

Figure 1 - Hypothetical model of the interrelationships between obesity, blood pressure and metabolic profile of climacteric women. Montes Claros (MG), Brazil, 2014/2015.

Note:BMI: Body Mass Index; $\mathrm{DBP}_{1}$ and $\mathrm{DBP}_{2}$ : Diastolic Blood Pressure in the $1^{\text {st }}$ and $2^{\text {nd }}$ measurements; HDL: High Density Lipoprotein; $\mathrm{SBP}_{1}$ and $\mathrm{SBP}_{2}$ : Systolic Blood Pressure in the $1^{\text {st }}$ and $2^{\text {nd }}$ measurements; TG: Triglycerides; WC: Waist Circumference; WHtR: Waist-to-Height Ratio.

This study was approved by the Ethics Committee, complying with the ethical precepts of resolution 466/2012, and was approved under number 817,166.

\section{RE S U L T S}

The sample comprised 874 women with a mean age of 51.05 ( \pm 7.2 years); most women were between 52 and 65 years old and had a partner; they reported non-white skin color, had attended elementary school I or II, did not work in formal jobs, were sedentary or irregularly active and were in the post-menopausal period. As to the variables related to obesity and metabolic profile, altered mean values were observed, considered inadequate to health, such as, WC>88.0; IMC>25.0; TG>150.0; HDL<0.50; WHtR>0.50 (Table 1) [1,20].

The Figure 2 presents the measurement models for the constructs blood pressure, obesity and metabolic profile. They describe the standardized factor weights (estimates allocated above the arrows) and the percentages of the total variability of each variable explained by its construct (estimates allocated above the rectangles. In the blood pressure measurement model (Figure 2A) all factor weights were high (>0.50), suggesting that the four manifest variables (SBP1, SBP2, DBP1 and DBP) are strongly correlated with the 
Table 1 - Characterization of the sample of women in menopause according to sociodemographic variables, physical activity practice, phases of menopause blood pressure, obesity indicators and metabolic profile. Montes Claros (MG), Brazil, 2014/2015.

\begin{tabular}{|c|c|c|c|c|}
\hline Categorical variables & & & $n$ & $\%^{*}$ \\
\hline \multicolumn{5}{|l|}{ Age group } \\
\hline 40 to 45 years of age & & & 236 & 27.9 \\
\hline 46 to 51 years of age & & & 241 & 26.8 \\
\hline 52 to 65 years of age & & & 397 & 45.3 \\
\hline \multicolumn{5}{|l|}{ Marital status } \\
\hline With partner & & & 560 & 63.1 \\
\hline Without partner & & & 314 & 36.9 \\
\hline \multicolumn{5}{|l|}{ Skin color ${ }^{* *}$} \\
\hline Not white & & & 714 & 82.8 \\
\hline Caucasian & & & 154 & 17.2 \\
\hline \multicolumn{5}{|l|}{ Education** } \\
\hline Medium/High & & & 281 & 31.8 \\
\hline Elementary II & & & 231 & 26.6 \\
\hline Elementary I & & & 358 & 41.6 \\
\hline \multicolumn{5}{|l|}{ Formal job ** } \\
\hline Yes & & & 347 & 40.4 \\
\hline No & & & 520 & 59.6 \\
\hline \multicolumn{5}{|l|}{ Physical activity } \\
\hline Active/very active & & & 114 & 13.0 \\
\hline Irregularly active & & & 480 & 54.9 \\
\hline Sedentary & & & 280 & 32.1 \\
\hline \multicolumn{5}{|l|}{ Climacteric phases ${ }^{* *}$} \\
\hline Pre-menopause & & & 214 & 24.4 \\
\hline Peri-menopause & & & 185 & 21.3 \\
\hline Post-menopause & & & 473 & 54.3 \\
\hline Numeric Variables & Mean & SD & Asymmetry $^{* * *}$ & Kurtosis $^{* * *}$ \\
\hline Age (years) & 51.05 & 7.19 & 0.34 & -0.78 \\
\hline $\mathrm{SBP} 1(\mathrm{mmHg})$ & 127.08 & 17.72 & 0.44 & 0.78 \\
\hline $\mathrm{SBP} 2(\mathrm{mmHg})$ & 125.19 & 17.66 & 0.47 & 1.00 \\
\hline $\mathrm{DBP} 1(\mathrm{mmHg})$ & 83.05 & 12.45 & 0.43 & 2.34 \\
\hline $\mathrm{DBP} 2(\mathrm{mmHg})$ & 81.86 & 11.41 & -0.12 & 0.49 \\
\hline WC $(\mathrm{cm})$ & 93.04 & 13.79 & -0.46 & 1.24 \\
\hline BMI $\left(\mathrm{kg} / \mathrm{m}^{2}\right)$ & 28.81 & 5.73 & 0.23 & 0.36 \\
\hline $\mathrm{WHtR}(\mathrm{cm})$ & 0.60 & 0.09 & -0.38 & 0.79 \\
\hline $\mathrm{TG}(\mathrm{mg} / \mathrm{dL})$ & 157.84 & 75.57 & 0.61 & 0.63 \\
\hline $\mathrm{HDL}(\mathrm{mg} / \mathrm{dL})$ & 41.09 & 10.26 & 0.81 & 0.12 \\
\hline Glycemia & 89.06 & 32.16 & 1.55 & 3.67 \\
\hline
\end{tabular}

Note: ${ }^{*}$ Corrected by the effect of the drawing (deff); ${ }^{* *}$ The totals vary due to losses; ${ }^{* * *}$ Values obtained after logarithmic transformation. BMI: Body Mass Index; DBP1 and DBP2: Diastolic Blood Pressure in the $1^{\text {st }}$ and $2^{\text {nd }}$ measurements; HDL: High Density Lipoprotein; SBP1 and SBP2: Systolic Blood Pressure in the $1^{\text {st }}$ and $2^{\text {nd }}$ measurements; SD: Standard Deviation; TG: Triglycerides; WC: Waist Circumference; WHtR: Waist-to-Height Ratio.

blood pressure construct, that is, the increase in blood pressure is reflected in the increase in SBP and DBP levels. All trajectories of the obesity construct (Figure 2B) also showed high factor weights $(>0.50)$ indicating a high correlation between the construct and the variables CA, BMI and WHtR, that is, high levels of obesity are reflected in higher values of WC, BMI and WHtR. In the metabolic profile construct (Figure 2C), only TG had a factor weight greater than 0.50 . The factorial estimates of this model suggest that a greater change in the metabolic profile is reflected in an increase in TG and glycemia levels and in a reduction in HDL. 


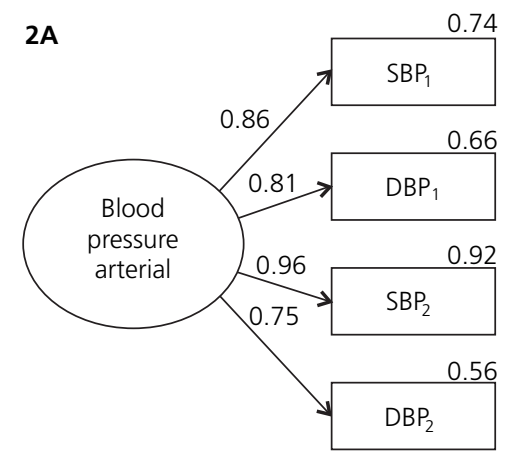

2B

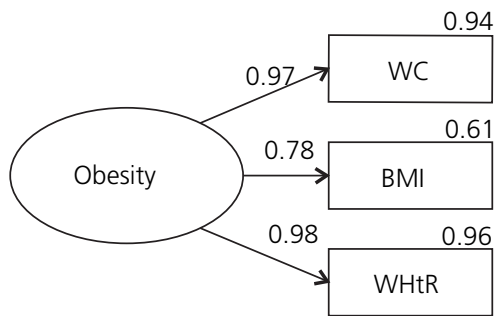

$2 \mathrm{C}$

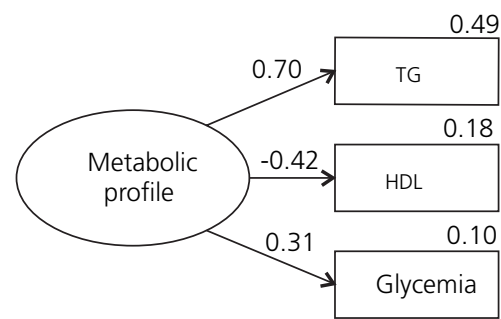

Figure 2 - Measurement models for blood pressure, obesity and metabolic profile of climacteric women. Montes Claros (MG), Brazil, $2014 / 2015$.

Note: *All manifest variables are on a logarithmic scale; BMI: Body Mass Index; DBP and $\mathrm{DBP}_{2}$ : Diastolic Blood Pressure in the $1^{\text {st }}$ and $2^{\text {nd }}$ measurements; HDL: High Density Lipoprotein; SBP 1 and $\mathrm{SBP}_{2}$ : Systolic Blood Pressure in the $1^{\text {st }}$ and $2^{\text {nd }}$ measurements; TG: Triglycerides; WC: Waist Circumference; WHtR: Waist-to-Height Ratio.

The adjusted structural model presented acceptable fit indexes $\left(\chi^{2} / d f=3.45 ; C F I=0.983 ; G O F=0.975\right.$; $\mathrm{TLI}=0.973 ; \mathrm{RMSEA}=0.05$ ( $\mathrm{Cl}: 0.04-0.06) ; p=0.292$. It was observed that age had a positive and significant effect on obesity $(\beta=0.10)$ and blood pressure $(\beta=0.20)$, indicating that the increase in age is correlated with the increase in these parameters. On the other hand, age was negatively correlated with the practice of physical activity $(\beta=-0.12)$, that is, with increasing age, women reduced the frequency of physical activity. There was no significant effect of age on the metabolic profile and of the metabolic profile on blood pressure There was also a positive effect of obesity on blood pressure $(\beta=0.26)$ and on the metabolic profile $(\beta=0.10)$, suggesting that the increase in the obesity indicators is correlated with increased blood pressure and metabolic levels. The practice of physical activity was negatively correlated with obesity $(\beta=-0.07)$, indicating that a higher frequency of physical activity is correlated with a reduction in obesity indicators (Table 2 and Figure 3).

Table 2 - Standard and non-standard coefficients estimates, with their relevant standard errors, for the interrelationships between blood pressure, obesity and metabolic profile of menopausal women. Montes Claros (MG), Brazil, 2014/2015.

\begin{tabular}{|c|c|c|c|c|}
\hline \multirow{2}{*}{ Effects } & \multicolumn{3}{|c|}{ Coefficient } & \multirow{2}{*}{$p$-value } \\
\hline & Standard & Non-standard & SE & \\
\hline \multicolumn{5}{|l|}{ Age effect on } \\
\hline Blood pressure & 0.20 & 0.18 & 0.03 & $<0.001$ \\
\hline Obesity & 0.10 & 0.11 & 0.04 & 0.004 \\
\hline Metabolic profile & 0.05 & 0.11 & 0.09 & 0.245 \\
\hline Physical activity & -0.12 & -0.53 & 0.16 & $<0.001$ \\
\hline \multicolumn{5}{|c|}{ Physical activity effect on } \\
\hline Blood pressure & 0.01 & 0.001 & 0.006 & 0.929 \\
\hline Obesity & -0.07 & -0.02 & 0.008 & 0.044 \\
\hline Metabolic profile & -0.02 & -0.009 & 0.02 & 0.635 \\
\hline \multicolumn{5}{|l|}{ Obesity effect on } \\
\hline Blood pressure & 0.26 & 0.23 & 0.03 & $<0.001$ \\
\hline Metabolic profile & 0.10 & 0.18 & 0.09 & 0.037 \\
\hline \multicolumn{5}{|c|}{ Metabolic profile effect on } \\
\hline Blood pressure & 0.02 & 0.004 & 0.02 & 0.826 \\
\hline
\end{tabular}

Note: SE: Standard Error 


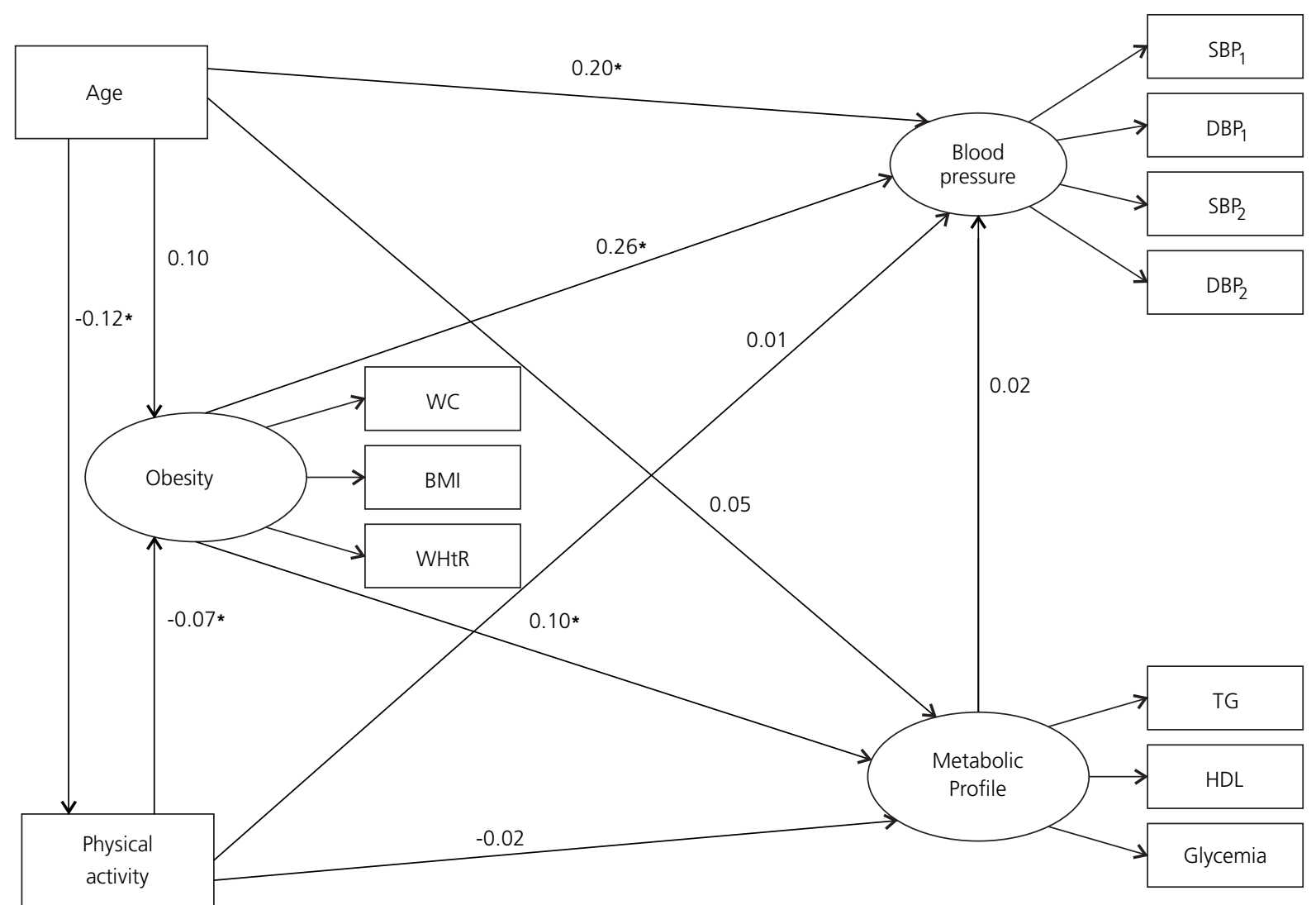

Figure 3 - Structural equation model of the interrelationships between blood pressure, obesity and metabolic profile of climacteric women. Montes Claros (MG), Brazil, 2014/2015.

Note: " $p<0.05 ; \mathrm{BMI}$ : Body Mass Index; $\mathrm{DBP}_{1}$ and $\mathrm{DBP}_{2}$ : Diastolic Blood Pressure in the $1^{\text {st }}$ and $2^{\text {nd }}$ measurements; HDL: High Density Lipoprotein; SBP 1 and $\mathrm{SBP}_{2}$ : Systolic Blood Pressure in the $1^{\text {st }}$ and $2^{\text {nd }}$ measurements; TG: Triglycerides; WC: Waist Circumference; WHtR: Waist-to-Height Ratio.

\section{DISCUSSION}

The present study investigated the interrelationships between obesity, blood pressure and metabolic profile in climacteric women adjusted for age, through the analysis of structural equations. This multivariate technique has been adopted in epidemiological studies, as it allows to analyze, simultaneously and not alone, a set of variables, in addition to allowing the incorporation of latent variables in the adjusted model $[17,28]$. The structural equation model adopted showed acceptable fit quality and suggests that, in this population, the ageing is correlated with the increase in obesity and blood pressure, just as higher obesity rates are correlated with increased blood pressure and altered metabolic profile.

Advancing age is a risk mechanism for increasing body weight and abdominal fat. Aging changes the composition and function of the adipose tissue, causing insulin resistance and ectopic lipid storage. A reduction in the activity of the brown adipose tissue, decreased levels of sex hormones and expansion of abdominal adipose tissue occur over the years through the redistribution of lipids from the subcutaneous to the visceral fat compartment [29]. Studies point to an average gain of $0.5 \mathrm{~kg}$ per year in climacteric women [22]. In this period of a woman's life, factors such as reduced energy expenditure and metabolism are responsible for obesity [30]. The adoption of inadequate health habits such as physical inactivity and excessive food intake have been commonly observed in the climacteric [31]. In addition, it is observed with 
advancing age the reduction of estrogen in the body, which favors the reduction of estradiol and elevation of leptin, hormones that regulate obesity and appetite [22].

Age also has an important influence on the increase in blood pressure [32]. A cohort study conducted with postmenopausal women found that the early age of natural menopause is associated with the prevalence of hypertension. Each 1-year delay in menopause has been associated with a $2 \%$ reduction in the prevalence of hypertension [33]. Arterial vessels stiffen with advancing age; this stiffness is due to the degree of fibrosis and calcification of the arterial walls. There is also a greater release of free radicals, which can lead to oxidative stress. This stress, in turn, favors the loss of nitric oxide, a vasodilator substance released by the endothelium, which consequently reduces the vasodilator capacity of the arteries. Both disorders are considered early markers of arterial hypertension [34].

In this study, a positive effect of obesity was found in altering blood pressure, which is consistent with the results of a previous study [35]. Retrospective cohort study with postmenopausal women found that the presence of obesity was associated with more than three-fold increased risk of incident hypertension [36]. The body with the presence of obesity presents an increase in arterial stiffness, thus causing an increase in blood pressure [37]. Obesity also indicates greater fat reserve, insulin resistance, salt retention and reduced physical activity, factors that influence blood pressure increase [35].

It was also observed that obesity showed a positive correlation with metabolic changes, corroborating the outcome of a previous study carried out in Estonia [38]. Investigations conducted with postmenopausal women seen at an outpatient clinic in southern Brazil found that Lipid Accumulation Product, altered blood glucose, low HDL and metabolic syndrome were more prevalent in overweight and obese women, when compared with eutrophic women [39]. The accumulation of abdominal fat in menopausal women is considered to be a critical factor for changes in the metabolic profile $[40,41]$. It is also noteworthy that insulin resistance caused by weight gain is an important component for increasing blood glucose in the body [42]. Visceral fat is associated with a high rate of lipolysis. The breakdown of triacylglycerol into glycerol and free fatty acid results in an increased flow of free fatty acids to the liver and increased resistance to hepatic insulin. One of the strategies for the treatment of insulin resistance involves the elimination of excess free fatty acids [41].

The interrelationships involving age, obesity, blood pressure and metabolic profile in women in menopause, found in this investigation, were also observed in previous studies [28]. Probably, these results can be explained by the profile of this sample, consisting of women in which the majority was in the post-menopausal period, sedentary, with high indicators of obesity and high levels of triglycerides, which average values are above the appropriate cut-off point for health.

A limitation of this study was the lack of information on insulin resistance, which did not allow inserting the construct diabetes in the structural model, suggested in both studies [28]. Another limitation of the study was the absence of correction due to the design effect (deff) in the adjustment of the measurement and structural models, since the IBM SPSS AMOS 22.0 statistical program was adopted which does not carry the implementation of this correction.

\section{CONCLUSION}

The simultaneous analysis of the relationships between age, obesity, blood pressure and metabolic profile in menopausal women showed that these variables are interrelated. This suggests that increasing age has an effect on the increase in obesity and blood pressure, just as obesity has a positive effect on the increase in blood pressure and changes in the metabolic profile. 
VMCP REIS, JSB ROCHA and MF SILVEIRA were responsible for the conception and design, analysis and interpretation of data, review and approval of the final version of the article. RS FREIRE, MFSF BRITO and L PINHO were responsible for reviewing and approving the final version of the article.

\section{REFERENCES}

1. North American Menopause Society. Guia da Menopausa. 7a. ed. São Paulo: Associação Brasileira Climatério; 2013.

2. Muka T, Oliver-Williams C, Kunutsor S, Laven JS, Fauser BC, Chowdhury R, et al. Association of age at onset of menopause and time since onset of menopause with cardiovascular outcomes, intermediate vascular traits, and allcause mortality: a systematic review and meta-analysis. Jama Cardiol. 2016;1(7):767-76.

3. Thurston RC, Chang Y, Barinas-Mitchell E, Jennings, JR, Känel RV, Landsittel DP, et al. Physiologically assessed hot flashes and endothelial function among midlife women. Menopause. 2017;24(8):886-93.

4. Marques MS, Freitas RF, Popoff DAV, Oliveira FPSL, Moreira MHR, Drummond AMA, et al. Health conditions associated with overweight in climacteric women. Plos One. 2019;14(12):e0218497. https://doi.org/10.1371/ journal.pone.0218497.s001

5. Wang HH, Lee DK, Liu M, Portincasa P, Wang DQ. Novel insights into the pathogenesis and management of the metabolic syndrome. Pediatr Gastroenterol Hepatol Nutr. 2020;23(3):189-230. https://doi.org/10.5223/ pghn.2020.23.3.189

6. Lockard B, Earnest CP, Oliver J, Goodenough C, Rasmussen C, Greenwood M, et al. Retrospective analysis of proteinand carbohydrate-focused diets combined with exercise on metabolic syndrome prevalence in overweight and obese women. Metab Syndr Relat Disord. 2016;14(4):228-37.

7. Adams-Campbell LL, Dash C, Kim BH, Hicks J, Makambi K, Hagberg J. Cardiorespiratory fitness and metabolic syndrome in postmenopausal African-American women. Int J Sports Med. 2016;37(4):261-6.

8. Wu HF, Tam T, Jin L, Lao XQ, Chung RY, Su XF, et al. Age, gender, and socioeconomic gradients in metabolic syndrome: biomarker evidence from a large sample in Taiwan, 2005-2013. Ann Epidemiol. 2017;27(5):315-22.

9. Tran BT, Jeong BY, Oh JK. The prevalence trend of metabolic syndrome and its components and risk factors in Korean adults: results from the Korean National Health and Nutrition Examination Survey 2008-2013. Bmc Public Health. 2017;17(71):1-8.

10. Park SA, Park WC, Kwon YJ, Shim JY. Association between the eating family meal and the prevalence of metabolic syndrome using data from Korea national health and nutrition examination survey (2007-2012). Korean J Family Med. 2017;38(3):130-4.

11. Lekoubou A, Ovbiagele B, Markovic D, Sanossian N, Towfighi A. Age, gender, and race/ethnic temporal trends in metabolic syndrome prevalence among individuals with myocardial infarction or stroke in the United States. J Neurol Sci. 2017;15(376):24-8.

12. Raposo L, Severo M, Barros H, Santos AC. The prevalence of the metabolic syndrome in Portugal: the PORMETS study. Bmc Public Health. 2017;17(555):1-9.

13. Bortoletto MSS, Souza RKT, Cabrera MAS, González AD. Síndrome metabólica, componentes e fatores associados em adultos de 40 anos ou mais de um município da Região Sul do Brasil. Cad Saúde Coletiva. 2016;24(1):32-40.

14. AkI LD, Valadares ALR, Gomes DC, Pinto-Neto AM, Costa-Paiva L. Factors associated with metabolic syndrome in middle-aged women with and without HIV. J Metab Syndr. 2016;5(2):1-5.

15. Kang Y, Kim J. Soft drink consumption is associated with increased incidence of the metabolic syndrome only in women. Br J Nutr. 2017;117(2):315-24.

16. Zurlo A, Veronese N, Giantin V, Maselli M, Zambon S, Maggi S, et al. High serum uric acid levels increase the risk of metabolic syndrome in elderly women: The PRO.V.A study. Nutr Metab Cardiovasc Dis. 2016;26(1):27-35.

17. Marôco J. Análise de equações estruturais: fundamentos teóricos, software \& aplicações. 2a. ed. Lisboa: Report Number; 2014.

18. Silva NN. Amostragem probabilística: um curso introdutório. 2a. ed. São Paulo: Editora da Universidade de São Paulo; 2004.

19. Matsudo S, Araújo T, Matsudo V, Andrade D, Andrade E, Oliveira C, et al. Questionário Internacional de Atividade Física (IPAQ): estudo de validade e reprodutibilidade no Brasil. Rev Bras Ativ Fís Saúde. 2001;6(2):5-12. 
20. Sociedade Brasileira de Cardiologia. VII Diretrizes Brasileiras de Hipertensão Arterial. Arq Bras Cardiol. 2016;107(3)3:1-83.

21. Chedraui P, San Miguel G, Vintimilla-Siguenza I, Villacreses D, Romero-Huete L, Dominguez A, et al. The metabolic syndrome and its components in postmenopausal women. Gynecol Endocrinol. 2013;29(6):563-8.

22. Yu TY, Jee JH, Bae JC, Jin SM, Baek JH, Lee MK, et al. Serum uric acid: a strong and independent predictor of metabolic syndrome after adjusting for body composition. Metabolism. 2016;65(4):432-40.

23. Karns R, Succop P, Zhang G, Sun G, Indugula SR, Havas-Augustin D, et al. Modeling metabolic syndrome through structural equations of metabolic traits, comorbid diseases, and GWAS variants. Obesity. 2013;21(12):745-54.

24. Huo D, Wang W, Li X, Gao Q, Wu L, Luo Y, et al. Evaluation of two single-factor models of metabolic syndrome: a confirmatory factor analysis for an adult population in Beijing. Lipids Health Dis. 2013;12(61):1-7.

25. Hair JF, Anderson RE, Tatham RL, Black WC. Análise multivariada de dados. 5a. ed. Porto Alegre: Bookman; 2005.

26. Kline RB. Principles and practice of structural equation modeling. 2nd. ed. New York: Guilford Press; 2005.

27. Vieira PRC, Ribas JR. Análise multivariada com o uso do SPSS. Rio de Janeiro: Editora Ciência Moderna Ltda; 2011.

28. Viitasalo A, Lakka TA, Laaksonen DE, Savonen K, Lakka HM, Hassinen M, et al. Validation of metabolic syndrome score by confirmatory factor analysis in children and adults and prediction of cardiometabolic outcomes in adults. Diabetologia. 2014;57(5):940-9.

29. Mancuso P, Bouchard B. The impact of aging on adipose function and adipokine synthesis. Front Endocrinol. 2019;11(10):137.

30. Seo SK, Yun BH, Chon SJ, Lee YJ, Han EJ, Park JH, et al. Association of serum ferritin levels with metabolic syndrome and subclinical coronary atherosclerosis in postmenopausal Korean women. Clin Chim Acta. 2015;1(438):62-6.

31. Medeiros MMC, Oliveira IMAX, Ribeiro ATM. Prevalence of metabolic syndrome in a cohort of systemic lupus erythematosus patients from Northeastern Brazil: association with disease activity, nephritis, smoking, and age. Rheumatol Int. 2016;36(1):117-24.

32. Singh S, Shankar R, Singh GP. Prevalence and associated risk factors of hypertension: a cross-sectional study in urban Varanasi. Inter J Hypert. 2017;2017:1-10.

33. Song L, Shen L, Li H, Liu B, Zheng X, Zhang L, et al. Age at natural menopause and hypertension among middle-aged and older Chinese women. J Hypertens. 2018;36(3):594-600.

34. Mikael LR, Paiva AMG, Gomes MM, Sousa ALL, Jardim PCBV, Vitorino PVO, et al. Envelhecimento vascular e rigidez arterial. Arq Bras Cardiol. 2017;109(3):253-8.

35. Khanal MK, Dhungana RR, Bhandari P, Gurung Y, Paudel KN. Prevalence, associated factors, awareness, treatment, and control of hypertension: findings from a cross sectional study conducted as a part of a community based intervention trial in Surkhet, Mid-western region of Nepal. Plos One. 2017;12(10):e0185806. https://doi.org/10.1371/ journal.pone.0185806

36. Stamatelopoulos K, Apostolakis M, Augoulea A, Paschou SA, Armeni E, Panoulis K, et al. Predictors of incident hypertension in healthy non-diabetic postmenopausal women with normal renal function. Gynecol Endocrinol. 2019;35(12):1063-6.

37. Yun BH, Chon SJ, Lee YJ, Han EJ, Cho S, Choi YS, et al. Association of metabolic syndrome with coronary atherosclerosis in non-diabetic postmenopausal women. Climacteric. 2015;18(2):284-9.

38. Kaldmäe M, Zemtsovskaja G, Abina J, Land T, Viigimaa M. Prevalence of cardiovascular disease risk factors in Tallinn, Estonia. Medicina (Kaunas). 2017;53(4):268-76. https://doi.org/10.1016/j.medici.2017.07.002

39. Fogaça e Silva EM, Theodoro H, Mendes KG, Anselmo Olinto MT. Prevalência de obesidade em mulheres na pósmenopausa atendidas em um ambulatório no sul do Brasil. Rasbran. 2019;10(1):46-52.

40. Ambikairajah A, Walsh E, Tabatabaei-Jafari $\mathrm{H}$, Cherbuin N. Fat mass changes during menopause: a metaanalysis. Am J Obstet Gynecol. 2019;221(5):393-409.e50. https://doi.org/10.1016/j.ajog.2019.04.023

41. Ko SH, Kim HS. Distúrbios metabólicos lipídicos associados à menopausa e alimentos benéficos para mulheres na pós-menopausa. Nutrients. 2020;12(1):202.

42. Udo T, McKee SA, White MA, Masheb RM, Barnes RD, Grilo CM. Menopause and metabolic syndrome in obese individuals with binge eating disorder. Eat Behav. 2014;15(2):182-5. 